\title{
FEATURES OF THE USE OF COLOR IN PROSE
}

\author{
Abiljon Abdurakhmonov
}

Doctor of Philology, PhD Department of Literature Fergana State University Fergana, Uzbekistan

\section{ABSTRACT}

The article discusses the properties of color in prose. Unlike a lyric work, prose comments on the use of color when expressing creative ideas. In the prose context, the static and dynamic manifestations of colors are given. The dynamic manifestation of colors in context is evidenced by examples of the repetition of the same color and the emergence of the primary color through its counterparts. It is also shown that the ratio of color to words and paragraphs in the context determines its importance in the expression of an artistic idea.

KEYWORDS:- Color, expression, artistic idea, context, statistics, static expression, dynamic expression, color scale, imagination.

\section{INTRODUCTION}

The theme of color has also been studied in different directions and from different points of view since ancient times throughout human development. Theoretical research on the aesthetic and chromatic issues of color was reflected in the religious-mythological and early natural philosophical views of antiquity in Europe [1]. In later periods, monographs on the nature of color appeared [2]. In this regard, the monograph study of S. Dondershine [3] on color and its specificity is important, the author has extensively studied the issue of color and through it the acquisition of identity in the psyche. In today's literature, research on the use of color in fiction continues. In our previous research, we studied the representation of color in a lyrical work according to its national character [4.105], euphonic properties [4.117], and grizzly style [4.118].

However, the peculiarities of the use of color in fiction, especially in prose, in the expression of creative ideas are not yet fully known to science. In this article, we would like to comment on such properties of color.

\section{Material AND METHODS}

It is well known that colors are used more differently in a prose work than in a lyrical work. We know that the color used in a lyrical work can be very symbolic, and even at the level of the image it can be a characteristic feature of its symbolic expression. In short, it is observed that each of the poetic images clearly loses its "color". From the above points of view, the situation is relatively different in prose works. Because in a prose play, ideas are far removed from being fixed and dimensional. This, in turn, frees the writer from the need to "express an idea in a few 
CURRENT RESEARCH JOURNAL OF PHILOLOGICAL SCIENCES 2(5): 24-27,

May 2021 DOI: https://doi.org/10.37547/philological-crjps-02-05-08

ISSN 2767-3758

(C)2021 Master Journals

\section{Crossref do) 81 Google}

Accepted25 $5^{\text {th }}$ May, 2021 \& Published 30 $0^{\text {th }}$ May, 2021

words". While the plot of a lyrical work is usually as scattered as the planets, the prose work moves more explicitly and visibly like a river flowing from a mountain to the ocean towards an artistic goal. As for the use of color in the play, this is exactly the process that takes place, as we have given above. That is, in a lyrical play, color may be used separately for "each planet". And this color and contrast serve in the poet's artistic thinking and serve to express the creative idea he wants to promote in a sharp and concrete way. (Because sharpness and concreteness are important aspects that characterize the lyrical type.) A single lyrical work can also refer to multiple colors. It is also possible to express a creative idea by applying two or even three colors in a single line. We observe this in the examples of our classical poetry. (For example, Navoi's "red, yellow, green" radiant ghazal [5].

The "planetary images" in the lyric can be reflected not only in the color of the "sun" in the center of the work, but also in their own colors.

We observe the use of colors in prose works in two cases:

1) Static representation of colors in prose context;

2) The dynamic manifestation of color in a prose context.

In the first case, in the prose play, there are almost no cases of sharp manifestations of colors, as described above. Because the plot of the prose work has a systematic structure, it carries the color of the artistic space "flowing" throughout the work. Therefore, the need to frequently refer to the color presented in a prose work as a lyrical work is not strong. In short, how much color is used in a prose work does not increase its influence in revealing the writer's artistic idea. What matters is what kind of "colorful space" that artistic source originally traveled through. That color eventually "hits" all the images, details, and other parts of the plot with its own symbolic expression.

This means that there will be works in which a certain color is applied one or more three or four times at the beginning of the statement. However, the "color" of this appeal will remain in the reader's memory until the end of the work. A writer who takes advantage of this opportunity will be able to effectively use the flashes and hues of that color to direct his artistic idea towards a creative goal. In doing so, it certainly relies on the symbolic expression of color.

2. The dynamic manifestation of colors in context. In this sense, the color in the prose is largely close to the status of leitmotifs. It comes to the same color in conjunction with the object to which it belongs, or as a quality of other objects. Such an expression of colors comes in two forms: 1) through the repetition of the same color itself; 2) through the shades of the primary color.

In the first case, we can cite the story of Olim Atakhan "Yellow window on the fourth floor" [6].

To determine the saturation of literary works with color, S.M. Solovev uses the amount of color: the number of color applications. (To determine the color saturation of literary works, the researcher S.M. Soloviev uses the color number: the number of references) [7.54-56]. He points out that the property of color can be revealed by relating it to the amount of application on the page of his work. In our opinion, determining the essence of expression depending on the page of the work of color is not considered perfection.

The story consists of 2,884 words in addition to the title and epigraph, and is made up of 70 headings, large and small. Yellow was applied 34 times. Through statistical analysis of the use of color, it is possible to determine the activity of color in the work and its prestige (priority) in artistic logic. This is done by determining the 
CURRENT RESEARCH JOURNAL OF PHILOLOGICAL SCIENCES 2(5): 24-27,

May 2021 DOI: https://doi.org/10.37547/philological-crjps-02-05-08

ISSN 2767-3758

(C)2021 Master Journals

\section{Crossref do) 81 Google}

Accepted25 $5^{\text {th }}$ May, 2021 \& Published 30 th May, 2021

percentage of color in the work relative to the word and paragraph. That is: 1) in the form of the ratio of color to the amount in the whole text;

2) In the form of the ratio of color to the number of paragraphs. As a result, it becomes clear to imagine the range of colors in the expression of an artistic idea. This process is given in the following formulas:

$\mathrm{S}$ - number of words, $\mathrm{R}$ - color, A- paragraphs, Pcoloration percentage

1. $(\mathrm{S}-\mathrm{R}) / \mathrm{S}=\mathrm{P} \quad 2884 /(2884-34)=9,8 \%$ Hence the color activity in the story $9,8 \%$.

2. $(\mathrm{A}-\mathrm{R}) / \mathrm{R}=\mathrm{P} . \quad(70-34) / 70=51,4 \%$ Color activity in paragraphs $51,4 \%$

According to our research, the presence of color in the story above $1 \%$ indicates that it belongs to the dynamic form. From this it is known that colors are more active in this story. In formula 2 (in relation to paragraphs), the means of artistic expression of color, the activity of which is determined, is the ability to direct an artistic idea as a leitmotif in paragraphs.

If we systematize the concepts of color that are added to it as a leitmotif in the play, a color map of the expression of a specific artistic idea emerges. We see this again in the example of Olim Atakhan's story "The Yellow Window on the Fourth Floor" [6]. The leitmotif of the "yellow window" is emphasized in connection with the following concepts:

1. Surprise. 2. Legendary bird. 3. Unoccupied area 4. Confidence. 5. Imagination. 6. Wait. 7. Employment. 8. Significance. 9. Imagination. 10. Nutrition. 11.Sweetheart. 12.Fantasy. 13.Captive. 14.Mystery. 15. The idea is fantastic. 16.Someone. 17. Learning. 18. The old cave. 19.Anyone. 20. Despair. 21.Companion (dropped off at the station). 22. Who is the suspect. 23. Elas-elas blinking. 24.Love. 25.Voice. 26. Poor man. 27. Compassion. 28. Visit. 29. Delightful. 30. Want to know.31.Clarification. 32. Consequences.
33. Suffering.

The yellow color in the story, according to its expressive nature, influences the concepts to which it is connected, and directs them to the expression of an artistic idea.

In the second case, the expression of an artistic idea through the counterparts of the primary color is interpreted mainly as the center of artistic logic in the psychoanalytic direction. Ulugbek Hamdam's story "Stone" is a vivid example of this. In the story, red is placed at the logical center, and its symbolic nature is subordinated to the dynamics of the plots of the whole work. In the play, the dynamic points of the plot of the red medium are intertwined.

"The crimson color of the setting sun was matched by the woman's half-dress and the red grains in it, so put it down: you would think that this is what the so-called harmony of the universe is all about. Filling his open shoulders, he awakened the look of a man with brown hair on his nose, and gave a legendary beauty to the young woman's existence that could only be imagined. In the wave of dawn that surrounded her, she swam as proudly as a red ship, and I kept my eyes on her." [ 8.518]

\section{Conclusion}

In conclusion, we observe that the narrator of the work carries the image in parallel on two levels: in the rhythm of the consistent depiction of events and experiences in the psyche and in the existence of the artistic space. The word "stone" in the work comes as a leitmotif, and its repetition emphasizes the artistic purpose, defines the path, and provides flow towards a particular object. The most striking aspect is that the image flow in the work is concentrated around the red color. It is as if the image of objects in the color of his family, which is characteristic of the spectrum of red, begins to appear. It should be noted that the passage 
CURRENT RESEARCH JOURNAL OF PHILOLOGICAL SCIENCES 2(5): 24-27,

May 2021 DOI: https://doi.org/10.37547/philological-crjps-02-05-08

ISSN 2767-3758

(C)2021 Master Journals

\section{Crossref do) 81 Google}

Accepted25 $5^{\text {th }}$ May, 2021 \& Published 30 th May, 2021

contains a number of shades of red: The purple of the setting sun; a woman's half-naked dress; red grains in it; the woman is like a red ship. The rotation of such shades of red along the spectral area further expands the area of the symbolic feature of the color. It is known that the color red not only comes as a symbol of happiness, joy, joy, but also represents negative concepts such as greed, blood, sacrifice, creating a diversity of concepts and the responsibility for a broad and deep observation of artistic logic through the complexities of psychoanalytic imagery. Red creates a vortex of a large stream of consciousness flow in thinking. As a result, the dynamics of the whole work is moved by the exact color. Throughout the next lines of the text, the flow of consciousness begins to be taken into account as it moves along the properties of the concept and symbolism that produce the exact color. As if the narrator brings the affected objects to the imagination against a background of red.

\section{ReFERENCES}

1. Theophrastus. About sensations // Serov N.V. Antique chromatism. SPB., 1995.

2. Alekseev S.S. Color science. - M .: Art, 1952. 148 p .; Mironova L.N. Color science. - Minsk: Higher school, P. 1984. - 287.

3. Dondershine S. Color and Identity in A.S.Byatt's Possession. San José State University. USA, California.1998.

4. Abdurakhmonov Abiljon Abdusamatovich, Poetic interpretation of light, color and psychology in uzbek poetry (in the aspect of tradition and novation). Dissertation abstract for doctor of philosophy in philological sciences (PhD).Fergana - 2018

5. Navoi. My black eyes. -Tashkent: A.C., 1988.

6. Scholar Atakhon. Yellow window on the fourth floor (story). Ziyouz.uz.11.04.2012 .
7. Soloviev S.M. Color, number and Russian literature // Knowledge is power.1971. № 1.

8. Ulugbek Hamdam. Stone. Story. A song about the homeland. Novels and stories.Tashkent: 2014

9. Abdurakhmonova, M. M., ugli Mirzayev, M. A., Karimov, U. U., \& Karimova, G. Y. (2021). Information Culture And Ethical Education In The Globalization Century. The American Journal of Social Science and Education Innovations, 3(03), 384-388.

10. Abdurashidovich K. A. Motivation and National Character of Foolishness in Uzbek Literature //ANGLISTICUM. Journal of the Association-Institute for English Language and American Studies - 2018 - Tashkent:. 7. - №. 4. - P. 47-51.

11. Qayumov A. CREATING OF A NATIONAL CHARACTER THROUGH MEANS OF LITERATURE //Theoretical \& Applied Science. - 2018. - №. 1. - P. 235-240.

12. Abdupattoev M. T. Unusual Connections As Forming Literary Text //The American Journal of Social Science and Education Innovations. - 2021. - Tashkent:. 3. - №. 02. - P. 177-182. 